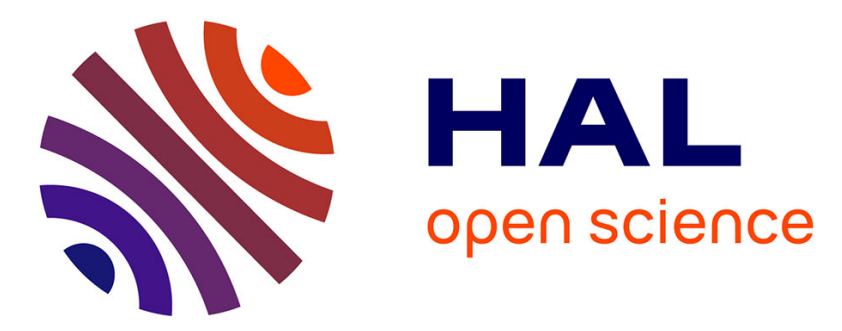

\title{
Preliminary Sizing of a Collaborative System: Photovoltaic Power Plant and Electric Vehicle Fleet
}

Roman Le Goff Latimier, Thibaut Kovaltchouk, Hamid Ben Hamed, B Multon

\section{To cite this version:}

Roman Le Goff Latimier, Thibaut Kovaltchouk, Hamid Ben Hamed, B Multon. Preliminary Sizing of a Collaborative System: Photovoltaic Power Plant and Electric Vehicle Fleet. Ecological Vehicles and Renewable Energies (EVER), 2014 Ninth International Conference on, Mar 2014, Monte-Carlo, France. 10.1109/EVER.2014.6844110 . hal-01225247

\section{HAL Id: hal-01225247 \\ https://hal.science/hal-01225247}

Submitted on 6 Nov 2015

HAL is a multi-disciplinary open access archive for the deposit and dissemination of scientific research documents, whether they are published or not. The documents may come from teaching and research institutions in France or abroad, or from public or private research centers.
L'archive ouverte pluridisciplinaire HAL, est destinée au dépôt et à la diffusion de documents scientifiques de niveau recherche, publiés ou non, émanant des établissements d'enseignement et de recherche français ou étrangers, des laboratoires publics ou privés. 


\title{
Preliminary Sizing of a Collaborative System: Photovoltaic Power Plant and Electric Vehicle Fleet
}

\author{
R. Le Goff Latimier, T. Kovaltchouk, H. Ben Ahmed, B. Multon \\ SATIE-CNRS, ENS Rennes \\ Campus de Ker Lann, 35170 BRUZ, France \\ Email: roman.legoff-latimier@ens-rennes.fr, thibaut.kovaltchouk@ens-rennes.fr, \\ Hamid.Benahmed@ens-rennes.fr, Bernard.Multon@ens-rennes.fr
}

\begin{abstract}
Simultaneous upcoming of photovoltaic generation and electric vehicles increases constraints on electric power system. This paper explores the possible synergy between these players so as to jointly improve the production predictability while ensuring a low carbon mobility. First a context is defined for this collaboration. It consists in the association of a photovoltaic producer and some electric vehicles owners so as to both manage the $\mathrm{EV}$ recharge and meet a day-ahead production commitment. Several currently studied questions such as commitment strategies or optimal charging can be transposed into the proposed context called collaborative system. Here, we mainly focus on its sizing in terms of PV rated power and number of vehicles. A simplified model of the system is thus realised, including a day ahead commitment and an optimal vehicle charging planning, based on deterministic vehicle characteristics.First results show a strong influence of the sizing on the potential added value of vehicles in this association. Then, we assess the impact of day-ahead production forecast quality by comparing persistence forecast with some meteorological data. It appears that other things remaining equal, an imprecise forecast will increase the optimal number of vehicles that are supposed to get into the collaborative system. Finally, the robustness of the charging planning is investigated.
\end{abstract}

Keywords-photovoltaic energy; electric vehicle; collaborative system; production forecast; smart charging; sizing; power generation planning; production commitment.

\section{NOMENCLATURE}

$\Delta T \quad$ time step of all time series

$\varepsilon_{\text {grid }}$ commitment gap

$[W]$

$A V \quad$ Added Value of electric vehicles into a collaborative system

$C_{\text {inc }}$ vehicles incomes: saved penalties

Le Goff Latimier, R., Kovaltchouk, T., Ben Ahmed, H., \& Multon, B. (2014, March). Preliminary sizing of a collaborative system: Photovoltaic power plant and electric vehicle fleet. In Ecological Vehicles and Renewable Energies (EVER), 2014 Ninth International Conference on (pp. 1-9). IEEE.

\begin{tabular}{|c|c|}
\hline$C_{\text {out }}$ & $\begin{array}{l}\text { vehicles outcomes: cost of the daily } \\
\text { charging }\end{array}$ \\
\hline$C_{p e n}^{n_{e v}}$ & $\begin{array}{l}\text { penalties amount for a } n_{e v} \text { vehicles col- } \\
\text { laborative system }\end{array}$ \\
\hline$C_{p e n}^{0}$ & $\begin{array}{l}\text { penalties amount for a single PV plant, } \\
\text { without vehicles } \\
{[€]}\end{array}$ \\
\hline$E_{e v}^{\sharp}$ & rated energy of vehicles batteries $[k W h]$ \\
\hline$E_{e v}^{0}$ & initial energy of vehicles batteries $[k W h]$ \\
\hline$H_{\text {start }}$ & arrival hour of vehicles $[-]$ \\
\hline$H_{\text {end }}$ & departure hour of vehicles \\
\hline$P_{e v}$ & power consumed by vehicles $\quad[W]$ \\
\hline$P_{e v}^{\sharp}$ & $\begin{array}{l}\text { rated power of the interconnection with } \\
\text { vehicles } \\
{[W]}\end{array}$ \\
\hline$P_{\text {grid }}$ & power injected to the grid \\
\hline$P_{\text {grid }}^{*}$ & commitment power profile \\
\hline$P_{p v}$ & photovoltaic power \\
\hline$P_{\text {shed }}$ & shed power \\
\hline$P_{e v}^{D+1}$ & $\begin{array}{l}\text { day ahead forecast of vehicles consump- } \\
\text { tion }[W]\end{array}$ \\
\hline$\widehat{P_{p v}^{D+1}}$ & $\begin{array}{l}\text { day ahead forecast of the photovoltaic } \\
\text { production } \\
{[W]}\end{array}$ \\
\hline$\widehat{P_{p v}^{D}}$ & $\begin{array}{l}\text { intraday forecast of the photovoltaic pro- } \\
\text { duction }\end{array}$ \\
\hline & number of vehicles \\
\hline & photovoltaic peak power \\
\hline
\end{tabular}

\section{INTRODUCTION}

Growing concerns around renewable electricity production compel us to look beyond its advantages in terms of low carbon content. We will here focus our attention on photovoltaic (PV) devices but similar investigations can be carried on others energy sources such as wind or ocean waves. As a matter of fact, the electricity production by means of photovoltaic (PV) panels presents a high variability and relatively low predictability. Under such characteristics, the spread of PV plants cannot but be limited as it brings about some additional stress on distribution and transportation networks, while increasing the need for spinning reserves. Canova et al. [1] were thus able to show that PV producers could cause 
voltage fluctuations, fostered by large line impedance and important solar capacity. Then increasing heavily the penetration rate would first require an important strengthening of the grid if no precautionary measure was introduced.

Various proposals are currently being put forward to take into account this poor predictability. For instance, the call for tenders [2] which is in force on the French island territories for PV plants above $250 k W_{c}$ requires that the photovoltaic operator commits himself some time ahead on its production profile. This profile should moreover respect a trapezoidal shape with a period of constant production during mid-day. As a consequence of such constraints, the addition of a storage device which would be coupled to the PV power plant is required. Studies like those of Ru et al. [3] suggest some methods to design a storage capacity associated with PV plants in the context of exchanges with the electrical network. The possibility to take advantage of fluctuations in the electricity price is also taken into account.

Furthermore, the development of electric vehicles (EV) causes additional constraints on the transmission and distribution network. Indeed, these vehicles represent a modification of the total energy demand distribution. Transportations which were previously ensured by liquid fuels are supposed to be more and more electricity seeker. It is therefore necessary to be able to convert more energy into the electricity form and to distribute this energy according to the charging requests of users. Drovtar and Landsberg [4] describe the impact that the emergence of these new consumers can have on a grid, using the Estonian example, just as Turker et al. [5] do on the French one. It is concluded that in order to integrate a significant share of the vehicle fleet, it is necessary to set up some tariff incentives so as to shift during the night the vehicles charging consumption [6].

However, concurrently to these constraints, electric vehicles do have the potential to bring new services to energy systems. Indeed, they represent a storage capacity which is connected to the electrical network most of the time, as mobility often represent a little share of the vehicle life. Opportunities associated to this scattered storage were highlighted by Kempton and Tomic [7]. First of all, even if the stored energy is limited in comparison with some others grid players, interconnection power and fast response of electric vehicle batteries can enable them to play a part within spinning reserves [8]. But Kempton and Tomic had already considered a particularly fruitful combination of electric vehicles with renewable energy sources. Indeed, the environmental performance of transportation must be considered from well to wheel. As a consequence trying to improve this performance through the use of electric vehicles involves to use some primary energy sources with a low environmental impact. The direct association of electric vehicles with renewable energy sources is therefore very relevant. On the one hand, photovoltaic production - as well as any intermittent production - could use vehicle batteries as a storage device spread out over the grid, so as to mitigate their production variability and improve their predictability. On the other hand, the vehicles would be charged with a production of sustainable energy. Many studies address this collaboration. For instance, Traube et al. [9] investigate the possibility of using vehicles batteries to compensate some fast variations of PV production during cloudy days so as to only send slow power slopes into the grid. Such a compensation will result in a high frequency variation of the charging power that might hasten batteries ageing. Guillou et al. [10] investigates the collaboration of a PV plant and electric vehicles fleet, but to maximize the self-consumption of the solar production. This minimisation of power exchanges with the grid could be seen as a zero commitment.

This paper then proposes as a first step to present a context for the direct collaboration of photovoltaic producers and electric vehicles users, in order to comply with a production commitment which would be communicated one day-ahead to the grid manager (section II). Within this context, different problems must be solved to achieve the operational management of the system. A breakdown of these problems and of their interactions will be proposed. Afterwards, section III will examine more specifically the sizing issue in terms of peak power and number of vehicles. The influence of the quality of the day-ahead production forecast will be specifically investigated.

\section{DESCRIPTION OF THE INVESTIGATED SYSTEM}

\section{A. A collaborative system}

Some contexts aiming at structuring the electric vehicles charging in order to allow their integration into the electrical network have already been proposed [7], [11]. The framework which is here proposed relies on the merging of the usual functions of electric vehicles aggregator and of intermittent electricity producer. The goal is to build an operator who could be considered from a grid manager point of view as a single actor, to some extent similar to a virtual power plant, but with a distributed storage capacity. In this framework, photovoltaic producer is subjected to a constraint of dayahead production commitment. Thus, the manager of the system has to announce today the power profile he 


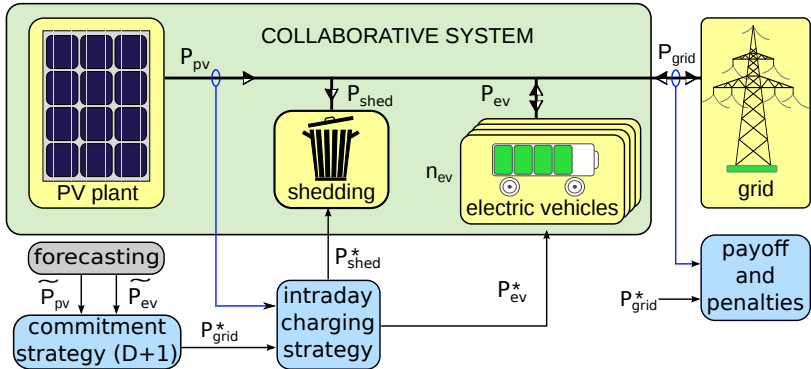

Figure 1. Outline schematic of the collaborative system players and main parameters.

might exchange with the grid during the following day. He suffers some penalties according to the gap between the profile he has committed and the profile he actually achieves to exchange. Therefore, he gets associated with some electric vehicles owners who entrust him the control of the battery charging power, subject to the requirement of a fully charged battery at the time they indicated when dropping their vehicle. The commitment constraint does not any more affect the single PV power profile, but is shifted to the power injected into the grid, which is the difference between the PV production and vehicles consumption. The possibility to shed some of the PV power is also taken into account. Such an association between a power plant and vehicles which stands as a mobile storage capacity is afterwards called collaborative system.

It may be noticed that the questions of physical interconnection of vehicles and power plant is not into the scope of this study. That means vehicles can either be in the direct neighbourhood of the PV plant or scattered over a large area but connected through the grid and collaborating with a distant plant. Although these two situations are very different, the management rules are in both cases similar. That is why the theoretical study that is here described does not exclude some remote collaboration, using the electrical network to gather the spread vehicles into a huge and virtual storage capacity. This second possibility does imply a complex infrastructure of communication and measurement, as well as a suitable regulatory framework and the absence of grid constraints. Each of these conditions represents an entire topic by itself and we only focus here on management investigations. Figure 1 presents the main actors in this system.

$P_{p v}$ stands for the maximum power that could be produced by the PV plant at a given instant. A share of this maximum achievable power can be shed $P_{\text {shed }}$ if there is no suitable solution to deliver it. Vehicles are overall consumers, but power flow can occasionally inverse in this specific context. Once again, this suppose to use some bidirectional battery chargers. $P_{e v}$ can thus be positive or negative. In the case where several vehicles are involved in the collaborative system, it becomes a vector quantity: $P_{e v}=\left\{P_{e v, 1}, \ldots, P_{e v, n_{e v}}\right\}$ with $n_{e v}$ the number of involved vehicles. A priori, the collaborative system is not supposed to strictly be an energy producer: power exchanged with the grid $P_{\text {grid }}$ can be bidirectional. Within this context, the objective is to obtain a power exchanged with the grid which is as close as possible to the commitment profile $P_{\text {grid }}^{*}$ taken out the day before. At any time, the system is ruled by the Kirchhoff law:

$$
P_{p v}=P_{g r i d}+P_{s h e d}+\sum_{i=1}^{n_{e v}} P_{e v, i}
$$

\section{B. Breaking down of the system management into sub- problems}

In order to manage a collaborative system, it is necessary to get some predictions of its behaviour, both in terms of maximum power output from the PV panels and of vehicle power needs. The latter is actually a forecast of the energy needed to refill the battery - how much energy ? - and of presence hours of the vehicles -when are they available ? These forecasts are written $\widetilde{P_{p v}^{X}}$ and $\widetilde{P_{e v}^{X}}$ where $X$ is the value of the prediction horizon. A dayahead forecast is written $D+1$ and an intraday forecast is written $D$. Based on day-ahead forecasts, the manager of the collaborative system must then be able to compute its commitment for grid exchanged power $P_{\text {grid }}^{*}$. real-time management of the vehicle charging power depends on both commitment - the objective to be strived towards - and real-time gathered information dealing with the solar irradiance and vehicles user behaviours. Finally a grid operator - a balance responsible party for instance - monitors the difference between commitment and actually achieved profile to determine what should be the payouts and penalties to be applied to the collaborative system. Several problems must be alternately solved to study the system. Figure 2 summarizes these problems and the interactions between them.

We can break down the collaborative system management into three entities :

- strategy of real-time vehicle charging. The goal is to find a way to determine the charging power depending on electricity production, availability and energy needs of vehicles so as to comply as much as possible with the grid commitment. It is therefore necessary to have decided upstream the commitment profile $P_{g r i d}^{*}$ as well as the collaborative system composition in terms of number of vehicles and peak power. 
- commitment strategy. It aims to compute the grid commitment profile for tomorrow based on day-ahead production forecasts $\widetilde{P_{p v}+1}$ and charging demand forecast $\widehat{P_{e v}^{D+1}}$. Knowledge of the system sizing is obviously necessary for such predictions, which can either come from an external specialized service or be produced internally by numerical methods.

- design of collaborative system. It appears than the decision which has to be made far upstream of the previous problems is the sizing of the collaborative system in terms of the peak power and number of involved vehicles.

Each one of the aforementioned issues is a complex question which is currently being investigated in other contexts and other systems. Among others, Peralta et al. [12] propose to determine production commitments within a framework where the consumption of domestic users is uncertain, using a joint chance-constrained programming method. Such an approach could be transposed to a situation where uncertainty is shifted from consumption to production. Furthermore, Vaya and Andersson [13]develop commitment strategies and vehicles charging programs that will allow to compensate forecasting errors of wind generation. In there study, the objective is to move the complexity towards the commitment strategy so as to get the real-time charging strategy simpler. On the contrary, Sortomme and El- Sharkawi [14] carry forward the complex task on the instantaneous charging management with an additional coupling with energy spot price. The model which describes vehicles is then deterministic.

\section{Scope of the further investigation}

This section has presented a context which involves electric vehicles and intermittent electricity producer into a collaborative system. In addition, a breakdown of issues that are to be solved in order to manage such a system

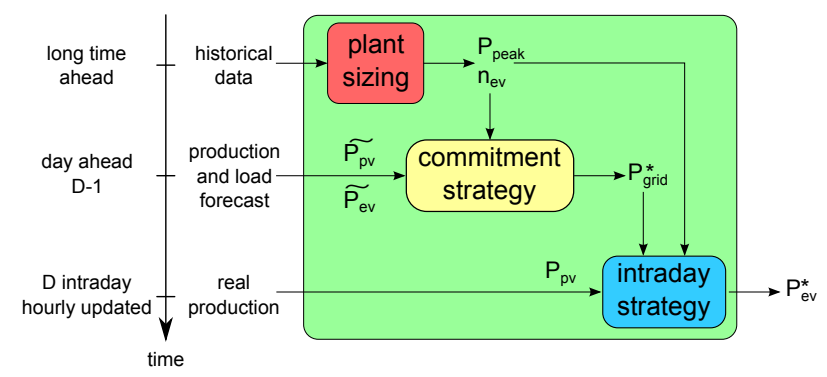

Figure 2. Outline of sub-problems occurring along the collaborative system management and connections among them. was presented. One could notice that several ongoing works consistently fit into the suggested context. The next section of this article tackles more specifically the issue of collaborative system sizing. As stated earlier, it is the very first problem on which both depend commitment and instantaneous charging power strategies.

\section{SYSTEM SIZING}

As mentioned in Section II, the design of the collaborative systems is crucial to build commitment and real-time charging strategies. The term design here stands for choosing the rated peak power of the PV system $P_{\text {peak }}$ and the number of cars it will collaborate with $n_{e v}$, which means the equivalent storage capacity as well as the interconnection power. However, to achieve this design study, it is necessary to get a relevant model which will take into account the entire system. One can hardly consider to model some of the complex management strategies that can be implemented for solving dayahead (D-1) commitment and real-time charging issues. Simplifying assumptions must be made so as to build a model which takes into account the whole system while maintaining a low level of complexity, consistent with the exploration of many design possibilities.

\section{A. System modelling and assumptions}

Most of the vehicles are used for a daily journey. Since the state of energy of an electric vehicle when it is dropped into the collaborative system mainly depends on its utilisation for mobility, it does not seem relevant to intent to develop charging strategies with an horizon farther than the coming evening. This model thus only considers optimisation throughout a day.

In order to determine the number of vehicles that might be associated to a PV plant of a given rated power $P_{\text {peak }}$, we seek to evaluate the added value of a given number of vehicles for the collaborative system. This added value is basically the difference between how much vehicles cost to the system and how much they make.

- how much vehicles cost: the energy needed to charge vehicles could otherwise had been injected into the grid. So as to assess the vehicles potential in terms of improving the overall system predictability, we consider that the daily charging of vehicles is ensured for free. The income loss is thus $C_{o u t}=n_{e v} . a .\left(E_{e v}^{\sharp}-E_{e v}^{\sharp}\right.$, where $E_{e v}^{0}$ the initial battery energy, $E_{e v}^{\sharp}$ the rated battery energy and $a$ the selling price to the grid manager. Here we assume $a=0.20 € / k W h$. This is a quite 


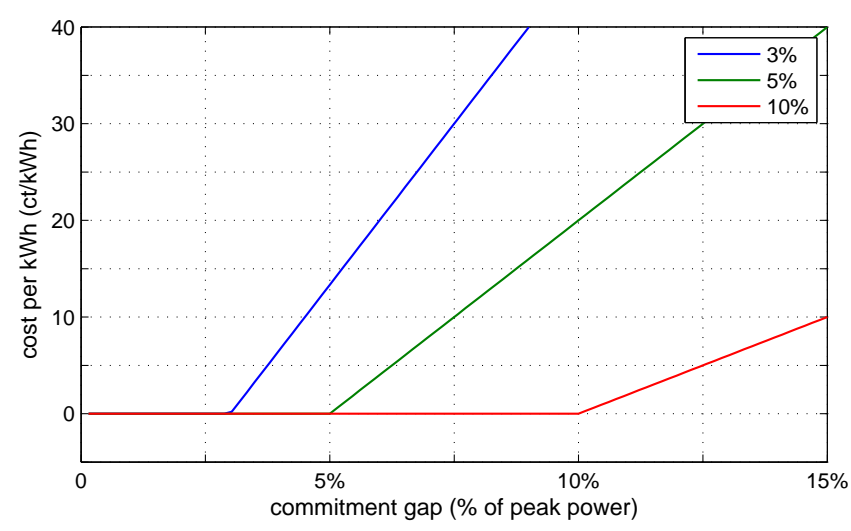

Figure 3. Penalisation law $C_{P e n}$ for three tolerance threshold values: $3 \% P_{\text {peak }}, 5 \% P_{\text {peak }}$ and $10 \% P_{\text {peak }}$

high value which can be justified by an insular context [2].

- how much vehicles make: the control of vehicles charging power allows the system to strive towards its commitment power profile $P_{\text {grid }}^{*}$ and thus avoid some penalties. Income is then the following reduction of penalties: $C_{i n c}=C_{p e n}^{0}-$ $C_{\text {pen }}^{n_{\text {ev }}}$ where $C_{\text {pen }}^{0}$ is the penalty amount for a single PV plant and $C_{\text {pen }}^{n_{e v}}$ for a collaborative system with $n_{e v}$ vehicles.

Our goal will thus be for the rest of the study to assess the added value of $n_{e v}$ vehicle within a collaborative system. This added value $A V$ is obviously the difference:

$$
A V=C_{\text {inc }}-C_{\text {out }}
$$

Computing penalties requires to choose a penalisation law. We adopt the shapes presented Figure 3. This law has as a parameter a tolerance threshold $\varepsilon$, expressed as a fraction of the plant peak power. Below this threshold, commitment gap $\varepsilon_{\text {grid }}=P_{\text {grid }}-P_{\text {grid }}^{*}$ is not penalized. Above, a linearly increasing penalty is applied to the exchanged power. An error corresponding to twice the threshold means that the penalty and the selling price are equal. I.e. if the commitment gap is greater than $2 \varepsilon$, injecting power into the grid would be a burden for the collaborative system.

We then need to proceed to a phenomenological modelling of the day-ahead commitment strategy and the instantaneous charging strategy. During a real operational management of the collaborative system, they would both use some complex methods and real-time information. As we here intent to achieve a sizing study, we will use time series of past records describing the production of a PV plant and the forecast of its production. The considered asset is a $2.64 \mathrm{MW}$ plant in Corsica island (France), monitored from May 2012 to April 2013 with a $\Delta T=15 \mathrm{~min}$ time step. Corresponding meteorological data are also available.

1) Day ahead commitment modelling: The first concern is the day-ahead commitment strategy. It has to be computed on the base of a production forecast $\widetilde{P_{p v}^{D+1}}$ and a prediction of the charging power profile of the vehicles $P_{e v}^{D+1}$. These forecasts are the ones available one dayahead $(D+1)$.

Assumption: deterministic behaviour of electric vehicles. All vehicles are considered identical and have the same driving patterns. Their individual storage capacity is $E_{e v}^{\sharp}=25 \mathrm{kWh}$, the interconnection rated power is $P_{e v}^{\sharp}=3 \mathrm{~kW}$. They are assumed to be available for the collaborative system between $H_{\text {start }}=9 \mathrm{a} . \mathrm{m}$. and $H_{\text {end }}=6 \mathrm{p} . \mathrm{m}$. and have an initial state of energy $E_{e v}^{0}=10 \mathrm{kWh}$. While this assumption may seem very restrictive, it roughly fits to the macroscopic behaviour of many fleets obeying working hours [14].

The $\widetilde{P_{e v}+1}$ forecast is thus a constant power profile from $H_{\text {start }}$ to $H_{e n d}$ which value is $n_{e v} \cdot \frac{E_{e v}^{\sharp}-E_{e v}^{0}}{H_{e n d}-H_{\text {start }}}$. The $\widetilde{P_{p v}^{D+1}}$ is in a first attempt done by a persistence forecast: the profile measured today is the forecast for tomorrow. Paragraph III-D will investigate the impact of this forecast technique. Grid commitment is then:

$$
P_{g r i d}^{*}=\widetilde{P_{p v}^{D+1}}-\widetilde{P_{e v}^{D+1}}
$$

2) instantaneous charging modelling: The next concern is the instantaneous charging strategy. An operational strategy might be based on tools like short terms models of the PV production, stochastic approaches or dynamic programming so as to take at each instant the best decision. Here, as we have to keep a low computational cost, it is not possible to implement such a real time strategy. We would instead try to determine a charging planning for the entire day, thanks to the PV production forecast $\widetilde{P_{p v}^{D}}$ which is available at the morning of the considered day.

Assumption: in a first attempt, it is supposed that $\widetilde{P_{p v}^{D}}$ is perfect. From the morning of a considered day, a perfect forecast of the coming production is available until the evening. This perfect prediction assumption from the morning may seem very strong. The paragraph III-E will aim to study how robust the chosen charging strategy is with respect to the forecast error. 


\section{B. Description of an optimisation problem}

Under the previously described modelling, the charging strategy can be computed as a linear optimisation problem:

$$
\min _{P_{\text {ev }}, P_{\text {shed }}} C_{P e n}^{n_{e v}}\left(P_{\text {grid }}^{*}-P_{\text {grid }}\right)
$$

such that

$$
\begin{aligned}
& E_{e v}(t)=E_{e v}^{0}+\Delta T \sum_{H_{\text {start }}}^{t} P_{e v}(\tau) \\
& \forall t \quad \in \quad\left[H_{\text {start }}, H_{\text {end }}\right], \\
& -n_{e v} \cdot P_{e v}^{\sharp} \leq P_{e v}(t) \leq n_{e v} \cdot P_{e v}^{\sharp} \\
& 0 \leq E_{e v}(t) \leq n_{e v} \cdot E_{e v}^{\sharp} \\
& E_{e v}\left(H_{\text {end }}\right) \geq 90 \% n_{e v} \cdot E_{e v}^{\sharp} \\
& \forall t \notin\left[H_{\text {start }}, H_{\text {end }}\right], \quad P_{\text {ev }}(t)=0
\end{aligned}
$$

I.e. the aim is to find the best charging planning $P_{e v}$ and production shedding planning $P_{\text {shed }}$ for the considered day so as to minimize penalties coming from the commitment gap. Constraints are the dynamic equation of the storage (5), maximum interconnection power of vehicles (6), extreme battery states of energy (7), charged battery at the outgoing hour (above $90 \%$ of full charge) (8) and zero power exchanged while batteries are not connected (9).

It may be noticed that the presented formulation is generic and could in the future be used to take into account some other system modelling including for instance random vehicles availability or imperfect forecast of future production. In the deterministic form which is here adopted, this optimization problem is solved with an interior point algorithm. Optimisation results over a 4 day sample is shown Figure 4. The time step is $15 \mathrm{~min}$.

This sample illustrates several different situations. During the first and fourth days, forecast has both underestimated the production and made temporary overestimations. Thus power shedding is used and batteries are punctually discharged to compensate the production lack. The second day is when the production has been quite well predicted by persistence. Thus the charging planning is very close to its day-ahead forecast $P_{e v}^{D+1}$, with a rectangular shape. Finally, the third day is a heavy overestimation case, when the grid commitment can not be fulfilled. Overall adequacy to the commitment profile is thus improved and therefore penalties lowered using vehicles charging power control. However, introducing vehicles into the system results in a diminution of the energy injected into the electrical network, and thus income losses. An optimum participation of electric vehicles is likely to exist.
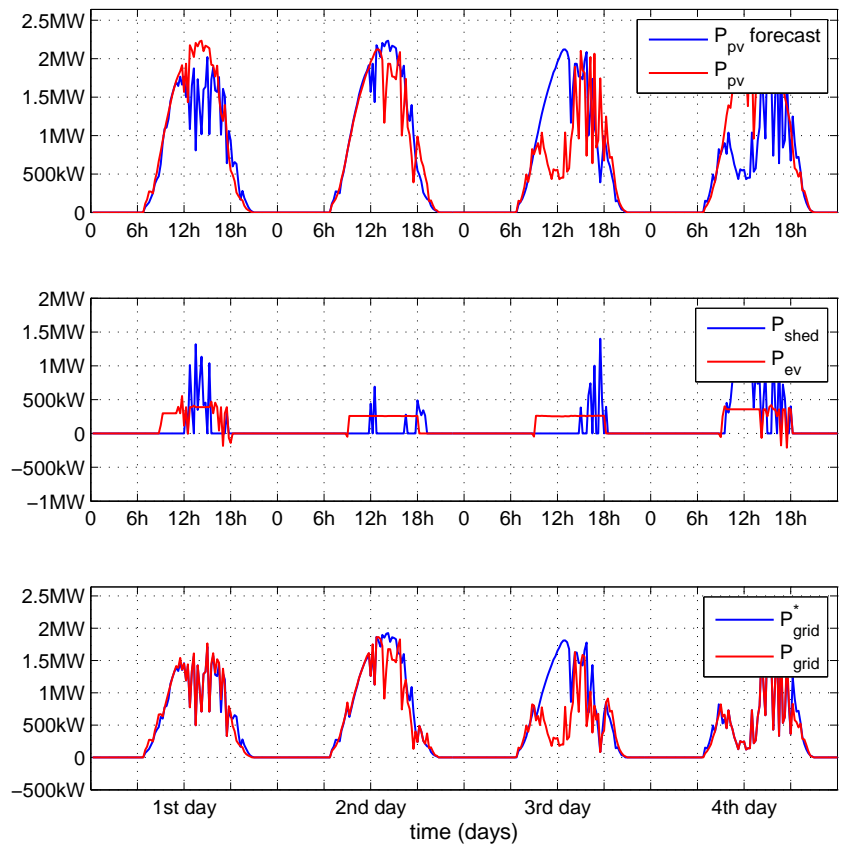

Figure 4. 4 day sample for a $\left\{P_{\text {peak }}=2.64 M W_{p}, n_{e v}=184\right\}$ collaborative system.

\section{Sizing results}

The design of a collaborative system such as we here consider requires a priori that we determine the value of the PV plant peak power and the number of vehicles involved into the association. Because of the way the problem has been set and of its characteristics, it can be noticed this design is only based on the ratio of these two quantities. Therefore the resolution of the previous optimization problem is iterated over a one year period and for different values of the $n_{e v} . E_{e v}^{\sharp} / P_{\text {peak }}$ ratio. The results depend on many parameters, not limited to the used time series describing the photovoltaic production and forecast, the supposed behaviour for vehicles, as well as the modelling assumptions. That is why the aim of the here presented results is not to propose predictions of profitability values, but rather to point out some tendencies that may be similar whatever the renewable sources and the storage system.

Results are shown Figure 5. The impact of penalisation law is investigated for three different values of the tolerance threshold, as represented Figure 3. The y-axis represent the added value $A V=C_{\text {inc }}-C_{\text {out }}$ over a one year period divided by the peak power $P_{\text {peak }}$. It is thus an annual benefit or loss by photovoltaic watt.

These results are indeed highlighting two very different sizing areas. In a first sizing region, there are not 


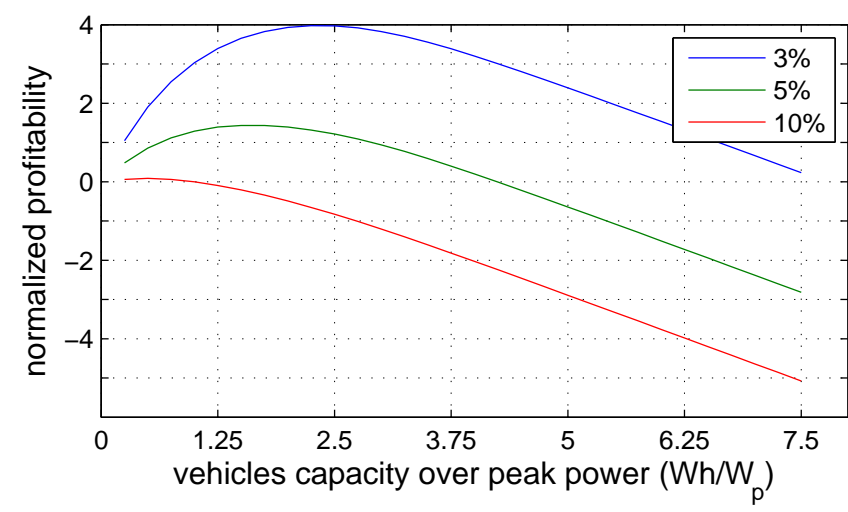

Figure 5. Evolution of the collaborative system profitability against $n_{e v} . E_{e v}^{\sharp} / P_{\text {peak }}$ ratio, over one year and for different tolerance thresholds.

enough vehicles to make the most from the potential of the collaboration. They do not represent a sufficient storage capacity to absorb the production forecast errors. On the contrary, if the vehicles are too numerous, an important share of the produced energy is dedicated to the batteries charging and thus is directly consumed. The residue that still can be sold to the grid manager is then no longer sufficient to compensate for the shortfall, even though compliance with the commitment were excellent. Two significant points can be discussed: the maximum profitability and the zero profitability. The position of these points necessarily depends on how the system is ruled by the penalisation law. On the first hand, if the law is stringent with a low tolerance threshold, collaboration is very relevant as a small storage capacity is able to save a large amount of penalties. On the other hand, if the penalty law is more tolerant, it becomes difficult to compensate for the energy absorbed by vehicles charging. In the median case, where the threshold is set at $5 \%$ of the peak power, sizing with maximum profitability is $1.7 \mathrm{Wh} / \mathrm{W}_{p}$, i.e. in a $2.6 \mathrm{MW}$ PV plant as the one used for production records, 180 vehicles with a $25 \mathrm{kWh}$ capacity. This represents a total storage capacity of $4.5 \mathrm{MWh}$ or a roughly 2 hours at $P_{\text {peak }}$. The energy needed for the daily charging of these vehicles is $2.7 M W h$ which means an hour of full power production. Concerning the zero profitability sizing point of $4.2 \mathrm{Wh} / W_{p}$, it is very close to a total self consumption of the entire production by vehicles.

We will now question in the two coming paragraphs the influence of the two forecast techniques used so far. The day-ahead production forecast $\widetilde{P_{p v}^{D+1}}$ has been made by persistence and the forecast for the current day from the morning $\widehat{P_{p v}^{D}}$ was a perfect prediction.
D. Influence of the day-ahead production forecast precision

So as to assess the influence of the $\widetilde{P_{p v}^{D+1}}$ day-ahead production forecast quality on the optimal sizing of the collaborative system, a comparison is carried between the three following cases, all other things remaining equal:

- the day-ahead production forecast is obtained by persistence (section III-C).

- the day-ahead production forecast is deduced from irradiance forecast which has been computed by Meteo France meteorologists, using the AROME numerical weather model.

- the time series used for day-ahead production forecast is a perfect prediction.

In particular, the forecast for the current day $\widetilde{P_{p v}^{D}}$ is still in this paragraph a perfect prediction. For the considered PV plant in Corsica, while persistence forecast has a mean squared error equal to $25 \%$ of the mean power output, the forecast coming from meteorologists lowers the error to $15 \%$ of the mean output. Figure 6 draws the comparison between computed profitability of the collaborative system for the three described cases.

It therefore appears that a better prediction greatly reduces the predicted added value of vehicles into a collaborative system. Indeed, if the manager of the plant can use a better forecast, he is thus able to compute a safer commitment. Penalties related to the commitment gap will then be necessarily lowered. Having a storage capacity to compensate for this gap will be less useful than in the case where the prediction and the realisation are very different. Added value is therefore generally reduced and the optimum sizing is shifted to a smaller number of vehicles, as it represents smaller energy need and a sufficient capacity storage regarding

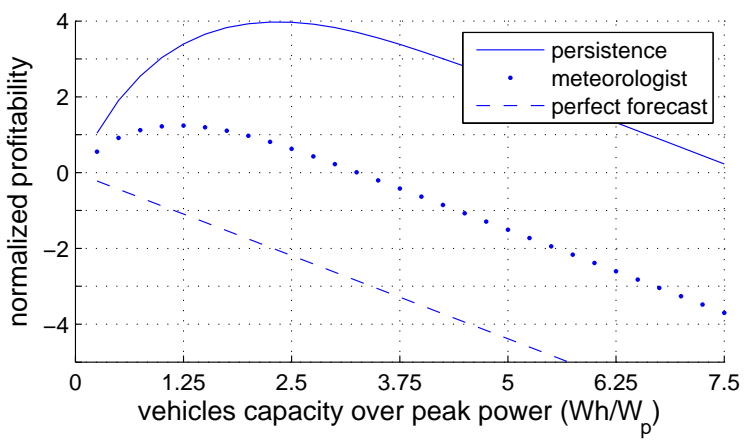

Figure 6. Impact of the day-ahead production forecast quality over the vehicles added value. The day-ahead commitment profile is computed using either a persistence forecast, a second one done by meteorologists and a perfect prediction. 
to low forecast errors. The extreme case is a perfect day-ahead production forecast. In such a situation, it is theoretically possible to get committed without any error. Providing a storage capacity to compensate for commitment gaps is no longer of any use. Moreover, as this storage capacity is also an overall energy consumer, it becomes a burden. The profitability of the collaborative system is then necessarily negative since it is always mandatory to charge the vehicles even when controlling their charging power is no longer useful. Profitability then decreases proportionally to the number of vehicles.

We here only focus on the system predictability issue. That is why if perfect forecast are available, storage device is of no interest. If we had tackled also the PV variability, a storage would have always been useful, even in perfect forecast situations.

It may be noticed that for heavily oversized systems, each one of the three investigated forecast techniques reaches the same asymptotic behaviour: a linearly decreasing profitability. It means that when the vehicles storage capacity is sufficient, the commitment gap has already been perfectly mitigated. There is thus no more penalty to save. But vehicles still cost some energy to the collaborative system.

\section{E. Robustness of the charging strategy with respect to current day forecast error}

We aims in this last paragraph to assess the consequences of the assumption of production perfect forecast from the morning and for the entire current day $\widetilde{P_{p v}^{D}}$. Whereas the charging power planning was previously computed with a perfect production prediction for the current day, we will now once again use a persistence forecast. The charging power profile is thus optimised on the basis of a forecast and not any more of the real achievement. It is then blindly applied to the real production profile. As a consequence, the profile of power exchanged with the grid is not the one guessed while optimising. This sensitivity study is made possible by the deterministic context. Even if the blindly applied charging planning does not suit the real PV production, it will not cause some inconsistency such as for instance extreme state of energy violations.

As the persistence forecast is here used for the intraday forecast $\widetilde{P_{p v}^{D}}$, the grid commitment strategy, based on a day-ahead forecast $\widetilde{P_{p v}^{D-1}}$, has to be computed with another prediction technique. Moreover, the $\widetilde{P_{p v}^{D-1}}$ should be of a poorer quality compared to $\widetilde{P_{p v}^{D}}$, as available information is supposed to increase as the clock is ticking. That is why a two days ahead persistence is here
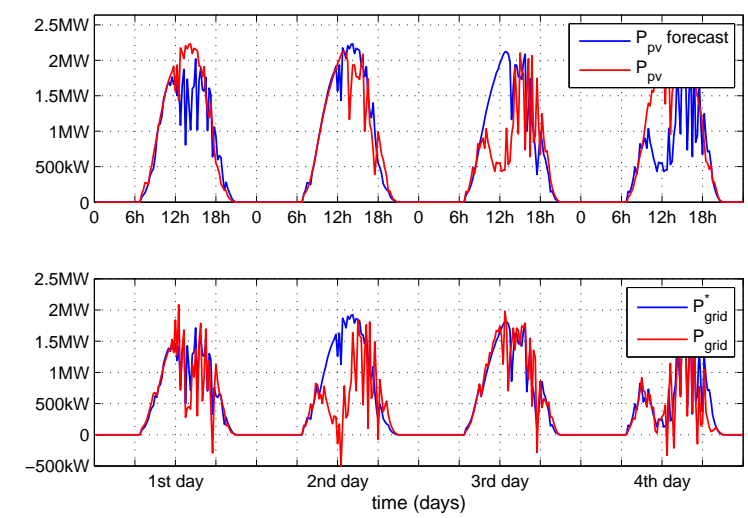

Figure 7. 4 day sample for a $P_{\text {peak }}=2.64 M W$ and $n_{e v}=184$ collaborative system. Impact of a persistence forecast for the current day production.

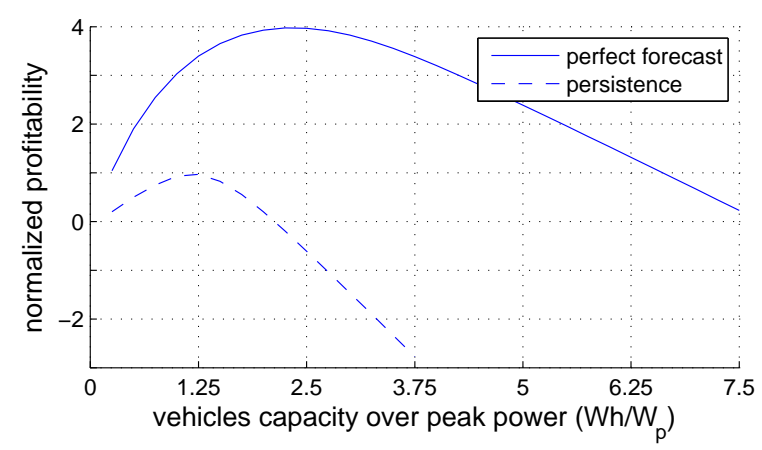

Figure 8. Impact of the intraday forecast quality over the vehicles added value.

used for $\widetilde{P_{p v}-1}$. The production profile measured today becomes the forecast for the day after tomorrow. Figure 7 illustrates this modification over the same sample as figure 4.

The profile of power exchanged with the grid is here necessarily downgraded in comparison with the perfect forecast case, regarding to commitment fulfilment. The degradation of performance is however highly dependent on the considered PV plant location. Corsica has a significant share of very sunny days when production forecast is very easy to achieve using a clear sky model. This characteristic reduces the impact of poor quality forecast. Performance is also dependent on the chosen modelling of the system. Figure 8 presents variations of vehicles added value depending on the forecast technique.

As vehicles charging is not optimal towards the real production profile, their added value is heavily lowered and the optimal sizing is shifted to fewer vehicles. 


\section{CONClusion}

In a first time, this study has presented a context for the collaboration between electric vehicles and photovoltaic plants. The management of such a collaborative system requires to solve several problems: a production commitment issue and a real-time charging strategy issue. Several independent and current research studies can fit into the context proposed here. In order to highlight the influence of the system sizing in terms of peak power and of electric vehicles number, a simplified modelling of the collaborative system behaviour is carried out. Under these assumptions, it is possible to show that the value of the ratio $n_{e v} E_{e v}^{\sharp} / P_{\text {peak }}$ - number of vehicles over PV peak power - set the overall system profitability. The influence of the production forecast quality over the profitability has been investigated by a comparison between performance achieved on a meteorologist based forecast and a persistence based forecast. It appeared that a poor quality day ahead forecast increases the added value of vehicles into the collaborative system. Indeed, the commitment gap - that has to be mitigated thanks to vehicles charging power planning - is more important.

The sizing which has been obtained under several modelling assumptions may be subject to further investigations. The impact of many of the parameters describing vehicles behaviour have not been been studied here. Moreover, it is possible to take into account more complex management rules for commitment and real time control and then to quantify optimal sizing modifications it would imply. Furthermore, a real time modelling would enable to implement some stochastic vehicles behaviours.

The strongest assumption made throughout this study aiming at a sizing proposal is that a perfect knowledge of the coming production is available from the morning and for the current day. It has be checked out that the profitability of collaborative system is strongly affected when production is not the one that was expected. Attempting to establish some robust charging policies regarding to the forecast error is thus one of the main investigation paths to yield a better performance.

\section{ACKNOWLEDGEMENT}

This study has been made possible thanks to the support of Langa Solar for the monitoring of its PV plant and Frank Baraer (Météo France) for the extraction of the corresponding meteorological data.

\section{REFERENCES}

[1] Canova, A. and Giaccone, L. and Spertino, F. and Tartaglia, M., Electrical Impact of Photovoltaic Plant in Distributed Network, in the Proc. of the IEEE Industry Applications Conference, 2007.
[2] Commission de Régulation de l'Energie, Cahier des charges de l'appel d'offres portant sur la réalisation et l'exploitation d'installations de production d'électricité à partir de l'énergie solaire d'une puissance supérieure à $250 \mathrm{kWc}, 2011$

[3] Yu Ru and Kleissl, J. and Martinez, S., Storage Size Determination for Grid-Connected Photovoltaic Systems, in the IEEE Transactions on Sustainable Energy, pp 68-81, vol 4, 2013.

[4] Drovtar, Imre and Landsberg, Mart, Large Scale Electric Vehicle Integration and its Impact on the Estonian Power System, in Proc. of the IEEE PowerTech Conference, Grenoble, 2013

[5] Turker, H., Bacha, S. and Chatroux, D., Impact of Plug-in Hybrid Electric Vehicles (PHEVs) on the French electric grid, in 2010 IEEE PES Innovative Smart Grid Technologies Conference Europe (ISGT Europe), 2010

[6] Rautiainen, A Mutanen, A and Repo, S and Jarventausta, P and Tammi, A and Helin, J and Ryymin, R, Case studies on impacts of plug - in vehicle charging load on the planning of urban electricity distribution networks, in Proc. of the EVER Conference, Monaco, 2013

[7] Kempton, Willett and Tomic, Jasna, Vehicle-to-grid power implementation: From stabilizing the grid to supporting large-scale renewable energy, Journal of Power Sources, Vol 144, pp 280294, 2005

[8] Han, Soohee and Sezaki, Kaoru, Development of an optimal vehicle-to-grid aggregator for frequency regulation, in IEEE Transsactions on Smart Grid, Vol 1, pp 65-72, 2010

[9] Traube, J, Lu, F, Maksimovic, D, Mossoba, J., Kromer, M., Faill, P., Katz, S., Borowy, B., Nichols, S., and Casey, L, Mitigation of Solar Irradiance Intermittency in Photovoltaic Power Systems With Integrated Electric-Vehicle Charging Functionality, Vol 28, n 6, pp 3058-3067, 2013

[10] Guillou, H and Cung, V.D. and Ha, D.L. and Jacomino, M. and Merten, J., Energy management Strategies for optima charging of vehicles with photovoltaic production, in Advanced GridConnected PV Systems, Book of Preprints, INES, pp 87-91, 2011

[11] Guille, C and Gross, G, A conceptual framework for the vehicle-to-grid (V2G) implementation in Energy Policy, Elsevier, Vol 37, n 11, pp 4379-4390, nov 2009

[12] Peralta, J J and Pérez-Ruiz, J. and de la Torre, S., Unit Commitment with Load Uncertainty by Joint Chance-Constrained Programming, in the Proc of the IEEE Powertech Conference, Grenoble, 2013

[13] Vaya, MG and Andersson, G, Integrating renewable energy forecast uncertainty in smart-charging approaches for plug-in electric vehicles, in the Proc. of the 2013 IEEE PowerTech Conference, Grenoble, 2013

[14] Sortomme, E and El-Sharkawi, M, Optimal Charging Strategies for Unidirectional Vehicle-to-Grid, in IEEE Transactions on Smart Grid, n 1, Vol 2, pp 131-138, 2011 